\title{
Article \\ Prevalence and Risk Factors for Post-Traumatic Stress in Hospitalized and Non-Hospitalized COVID-19 Patients
}

\author{
Gunnar Einvik ${ }^{1,2}$, Toril Dammen ${ }^{3}$, Waleed Ghanima ${ }^{2,4}$, Trond Heir ${ }^{2,5}$ (D) and Knut Stavem ${ }^{1,2,6, *(1)}$ \\ 1 Pulmonary Department, Akershus University Hospital, 1478 Lørenskog, Norway; \\ gunnar.einvik@medisin.uio.no \\ 2 Institute of Clinical Medicine, University of Oslo, 0450 Oslo, Norway; waleed.ghanima@so-hf.no (W.G.); \\ trond.heir@medisin.uio.no (T.H.) \\ 3 Department of Behavioral Medicine, Institute of Basic Medical Sciences, University of Oslo, 0317 Oslo, \\ Norway; toril.dammen@medisin.uio.no \\ 4 Haematology and Oncology, Østfold Hospital Trust Kalnes, 1714 Grålum, Norway \\ 5 Norwegian Centre for Violence and Traumatic Stress Studies, 0484 Oslo, Norway \\ 6 Health Services Research Unit, Akershus University Hospital, 1478 Lørenskog, Norway \\ * Correspondence: knut.stavem@medisin.uio.no
}

Citation: Einvik, G.; Dammen, T.; Ghanima, W.; Heir, T.; Stavem, K. Prevalence and Risk Factors for Post-Traumatic Stress in Hospitalized and Non-Hospitalized COVID-19 Patients. Int. J. Environ. Res. Public Health 2021, 18, 2079. https:// doi.org/10.3390/ijerph18042079

Received: 24 December 2020

Accepted: 18 February 2021

Published: 20 February 2021

Publisher's Note: MDPI stays neutral with regard to jurisdictional claims in published maps and institutional affiliations.

Copyright: (c) 2021 by the authors. Licensee MDPI, Basel, Switzerland. This article is an open access article distributed under the terms and conditions of the Creative Commons Attribution (CC BY) license (https:// creativecommons.org/licenses/by/ $4.0 /)$.

\begin{abstract}
This population-based study assessed the prevalence and determinants of symptomdefined post-traumatic stress disorder (PTSD) in a cohort of hospitalized and non-hospitalized patients about 1.5-6 months after their COVID-19 onset. The data were acquired from two mixed postal/web surveys in June-September 2020 from patients all aged $\geq 18$ years with a positive polymerase chain reaction for severe acute respiratory syndrome Coronavirus-2 (SARS-CoV-2) until 1 June 2020, comprising both hospitalized and non-hospitalized subjects. The catchment areas of the two included hospitals covers about $17 \%$ of the population of Norway. In total, 211 hospitalized and 938 non-hospitalized subjects received invitation. The prevalence of symptom-defined PTSD was assessed using the PTSD checklist for DSM-5 (PCL-5). Determinants of symptom-defined PTSD and PTSD symptoms were analyzed using multivariable logistic and linear regression analysis. In total, 583 (51\%) subjects responded at median 116 (range 41-200) days after COVID-19 onset. The prevalence of symptom-defined PTSD was $9.5 \%$ in hospitalized and $7.0 \%$ in non-hospitalized subjects $(p=0.80)$. Female sex, born outside of Norway, and dyspnea during COVID-19 were risk factors for persistent PTSD symptoms. In non-hospitalized subjects, previous depression and COVID-19 symptom load were also associated with persistent PTSD symptoms. In conclusion, COVID-19 symptom load, but not hospitalization, was associated with symptom-defined PTSD and PTSD symptom severity.
\end{abstract}

Keywords: post-traumatic stress disorder; COVID-19; cohort study; outpatients; hospitalized; intensive care unit

\section{Introduction}

The coronavirus disease 2019 (COVID-19) has to date affected more than 100 million people worldwide [1]. The proportion of cases in Norway having severe disease requiring hospitalization is about $5 \%$, however, in the early phase of the pandemic, $13 \%$ of all cases were hospitalized [2]. Severe COVID-19 is characterized by dyspnea, chest pain, or confusion and $12 \%$ of hospitalized patients have critical illness requiring care in the intensive unit. In the general population, there is considerable concern about being infected [3], and social isolation and quarantine for several weeks or months may have important social and psychological impacts.

Post-traumatic stress disorder (PTSD) is a chronic and debilitating mental condition that may develop in response to catastrophic life events, including critical medical conditions. According to a meta-analysis, $17-44 \%$ of critical illness survivors report clinically 
important PTSD symptoms [4]. How COVID-19, with or without critical illness, impacts long-term PTSD is unknown, however, according to data from other medical conditions, the severity of the medical condition is likely to determine the future risk for PTSD. Studying symptoms of PTSD and their determinants after COVID-19 may therefore be important to inform about the prognosis of COVID-19, identify possible modifiable risk factors, and identify vulnerable patients to enable early intervention [5].

The few follow-up studies of survivors 1-3 months after COVID-19 hospitalizations have reported significant PTSD symptoms among $12-22 \%$, as measured by the PTSD symptom checklist for DSM 5 (PCL-5) [6-8]. Non-hospitalized subjects constitute a much larger patient group than those hospitalized, and to the best of our knowledge, no previous study has assessed PTSD symptoms several months after COVID-19 in a consecutive sample of both hospitalized and non-hospitalized patients in a population-based study. Furthermore, studies on risk factors for the development of PTSD symptoms in patients after COVID-19 are scarce. It is, however, unknown whether the potential influence by COVID-19 on persistent PTSD symptoms is related to risk factors for PTSD in general (female sex, living alone, history of depression), COVID-19 symptom load, or the impact of hospitalization.

In this study, we aimed to determine if the prevalence of symptom-defined PTSD 1.5-6 months after confirmed COVID-19 was higher in hospitalized than non-hospitalized subjects. We also aimed to determine risk factors for persistent symptoms of PTSD in COVID-19 survivors.

\section{Materials and Methods}

\subsection{Design and Population}

In this study, we reported data from cross-sectional surveys of subjects in two parallel longitudinal cohort studies covering an identical geographical area of Norway representing $17 \%$ of the Norwegian population, conducted by the same research group.

\subsubsection{Survey of Hospitalized Subjects}

The patient-reported outcomes and lung function after hospitalization for COVID-19 (PROLUN) study invited subjects $4-8$ weeks after being discharged from a COVID-19related hospital stay to participate in a follow-up study with electronic or paper questionnaires and a clinical visit about 3 months after discharge [9]. The present study includes only subjects discharged before 1 June 2020, and who resided in the catchment area of Akershus University Hospital and Østfold Hospital Trust Kalnes.

\subsubsection{Survey of Non-Hospitalized Subjects}

The patient-reported outcomes and thromboembolic disease in COVID-19 (PROTROM) study recruited subjects residing in the catchment areas of Akershus University Hospital and Østfold Hospital Trust Kalnes that by 1 June 2020, had a positive polymerase chain reaction test for severe acute respiratory syndrome-Coronavirus-2 (SARS-CoV-2) from one of the two hospital laboratories or from the largest private laboratory in the region (Fürst laboratory). By the end of June 2020, 1-4 months after a positive test, 938 subjects were invited by mail for study participation. They could choose to respond to a paper or an online version of the questionnaire. After about 5 weeks, we sent a postal reminder to non-respondents. Details of the study design have previously been reported [10].

In total, 125/211 (59\%) in PROLUN and 458/938 (49\%) in PROTROM consented to participate, representing $51 \%$ of all eligible alive SARS-CoV-2 positive subjects $>18$ years in this geographical area and during this time period (Figure 1). 


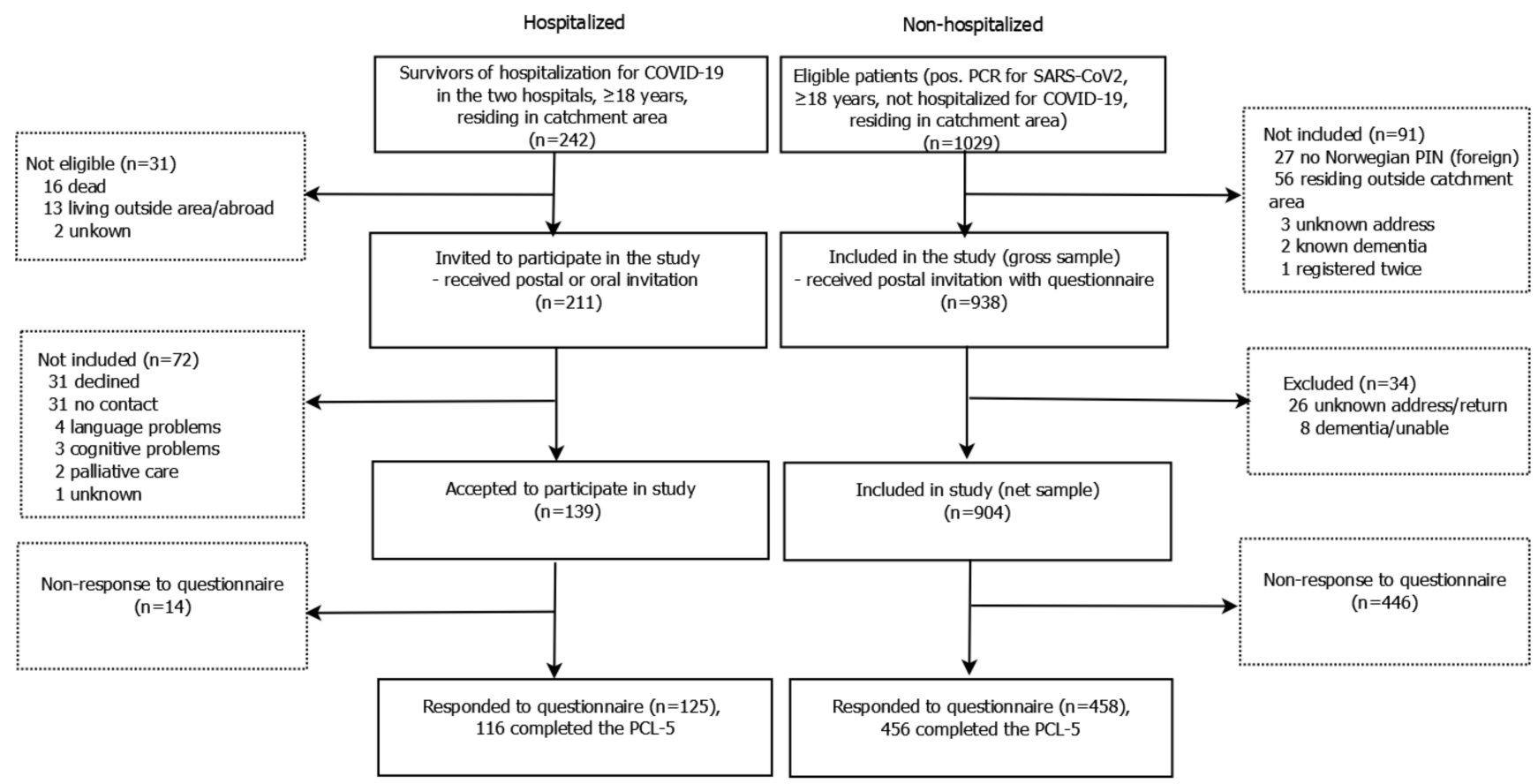

Figure 1. Flow chart of studies. PCL-5, post-traumatic stress disorder symptom checklist for DSM-5 (PCL-5); PCR, polymerase chain reaction; SARS-CoV-2, severe acute respiratory syndrome Coronavirus-2.

\subsubsection{Ethical Considerations}

All participants signed a written or digital consent form prior to completing questionnaires. The Regional Committees for Medical and Health Research Ethics, Health Regon South East (PROLUN approval no.2020/125384, PROTROM approval no. 2020/149384) and the Data Protection Officer at Ahus approved both studies. PROLUN is registered in ClinicalTrials.gov (NCT04535154).

\subsection{Data Collection and Assessments \\ 2.2.1. Assessment of PTSD}

Symptoms of PTSD were assessed using the PCL-5 [11,12]. This questionnaire contains 20 items on an ordinal scale ( 0 to 4 ), which are aggregated into a total sum-score (range $0-80$, with 80 denoting maximal symptom severity the past month). The PCL-5 also has an alternative scoring algorithm according to the DSM- 5 criteria, requiring a score of $\geq 2$ on 1 of 5 items in the Intrusion cluster, 1 of 2 in Avoidance, 2 of 7 in Cognition and mood, and 2 of 6 in Arousal and reactivity [13]. We used the DSM- 5 scoring to define the caseness of PTSD based on self-reported symptoms. The Norwegian PCL-5 was developed through a translation-back-translation procedure and has been used in previous studies [14].

\subsubsection{Assessment of Comorbidity and COVID-19 Symptoms}

In the survey of non-hospitalized subjects, comorbidity was self-reported using a checklist of 21 physician-diagnosed conditions, 18 of which constituted a self-report version of the Charlson comorbidity index [15] and additional items that we thought might be of interest in regard to the vulnerability for PTSD after COVID-19 including: history of depression, venous thromboembolism and more details on pulmonary comorbidity. In the hospitalized subjects, the Charlson comorbidity index [16] was collected by the review of electronic medical records (EMR) by trained physicians or nurses. Because of differences in data collection mode for comorbidities, we harmonized the comorbidities to represent the 16 most commonly occurring comorbidities/conditions. The number of these comorbidities was categorized as $0,1, \geq 2$ comorbidities. 
Non-hospitalized subjects retrospectively recorded the presence or absence of 23 symptoms related to COVID-19 [17]. In hospitalized subjects the presence or absence of COVID19 symptoms were assessed by study physicians or nurses by reviewing the EMR related to the hospitalization. For those subjects the list of symptoms contained a few less symptoms than the study of non-hospitalized subjects, therefore the harmonization of all symptom variables between the two studies was not possible. From symptom assessments, we only included fever and dyspnea, because they were identically assessed and rated, as absent $=0$ or present $=1$, across the two studies.

\subsection{Statistical Analyses}

The characteristics of the participants are presented as the mean (SD), median (interquartile range or range) or number (\%), as appropriate. We compared descriptive variables using the $t$-test for continuous variables, and chi-squared or Fisher's exact test for categorical variables. Most missing values were for place of birth or marital status, which we considered difficult to impute. There were $\leq 2 \%$ missing values for other variables; therefore, we did not impute missing values.

The crude prevalence of PTSD according to DSM- 5 was compared between groups using the chi-squared test. In addition, we present PTSD symptoms ( $0-80$ range) as continuous scores. Determinants of symptom-defined PTSD were analyzed by multivariable logistic regression in the combined data set with common variables in the two samples. As we had 43 cases with symptom-defined PTSD, we estimated prior to analysis to include a maximum of five independent co-variables in the logistic regression models. In addition to hospitalized vs. non-hospitalized, we included the following independent variables in the models based on the literature and what we thought might be important: age (per decade), sex, living alone (married/cohabiting vs. single/divorced/widowed), born in Norway (yes vs. no) and time since COVID-19 onset (above vs. below the median of 116 days). All these variables were entered into the multivariable models without any statistical selection procedure.

Determinants of PTSD symptoms (continuous PCL-5 total scale) were analyzed using multiple linear regression analysis. Because the distribution of responses on this variable was highly skewed with many subjects having a score of 0 , we attempted log and square-root transformations of the PCL-5 total scale. However, this did not improve the distribution of the residuals or the model fit. Therefore, we used multiple linear regression analysis of untransformed values, using bootstrapping with 10,000 iterations to estimate $95 \%$ confidence intervals. This analysis was conducted in the combined data set with common variables in the two samples (model 1); stratified for hospitalized (model 2) and non-hospitalized (model 3), in the non-hospitalized sample, with a richer set of variables (model 4).

In models 1, 2, and 3, we included age (per decade), sex, living alone (married/cohabiting vs. single/divorced/widowed), born in Norway (yes vs. no), time since COVID-19 onset (above vs. below the median of 116 days), education (three levels), number of comorbidities $(0,1, \geq 2)$, and two symptoms (fever, dyspnea) in the models. Hospitalization vs. non-hospitalization was added only in model 1. Finally, for model 4 we replaced fever and dyspnea with the number of 23 self-reported acute COVID-19 symptoms categorized in tertiles; $0-5,6-9,10-23$, and separately entered a symptom of confusion (as a possible marker of severe disease), as well as a history of depression (yes vs. no). There was no indication of collinearity, as assessed using Spearman correlations and variance inflation factor.

We used Stata (version 16.1, Stata Corporation, College Station, TX, USA) for all statistical analyses, using a significance level of $p<0.05$ in two-sided tests.

\section{Results}

\subsection{Study Population}

The hospitalized subjects were older, comprised a larger proportion of men, had less education, and included a lower proportion of subjects born in Norway (Table 1). 
Moreover, hospitalized subjects had more asthma, hypertension, diabetes and several other comorbidities than non-hospitalized individuals, and they more often had dyspnea or fever during COVID-19.

Table 1. Descriptive statistics for respondents in the two cohorts $(n=583)$, number $(\%)$ unless otherwise stated.

\begin{tabular}{|c|c|c|c|c|c|}
\hline & \multicolumn{2}{|c|}{$\begin{array}{l}\text { Hospitalized } \\
\quad(n=125)\end{array}$} & \multicolumn{2}{|c|}{$\begin{array}{c}\text { Non-hospitalized } \\
\quad(n=458)\end{array}$} & \multirow[t]{2}{*}{$p$} \\
\hline & $n$ & & $n$ & & \\
\hline Age, date of response, mean (SD) & 125 & $57.7(14.2)$ & 458 & $49.6(15.3)$ & $<0.001$ \\
\hline Sex, males & 72 & $(58)$ & 202 & $(44)$ & 0.007 \\
\hline Highest attained education $(\mathrm{n}=123 / 458)$ & & & & & $<0.001$ \\
\hline Primary school (<11 years) & 33 & $(27)$ & 41 & (9) & \\
\hline Secondary school (11-13 years) & 43 & (35) & 174 & (38) & \\
\hline University ( $>13$ years) & 47 & $(38)$ & 243 & (53) & \\
\hline \multicolumn{6}{|l|}{ Marital status ( $\mathrm{n}=112 / 457)$} \\
\hline Married/cohabiting & 77 & (69) & 336 & $(74)$ & 0.31 \\
\hline Born in Norway $(n=112 / 454)$ & 70 & (63) & 382 & $(84)$ & $<0.001$ \\
\hline \multicolumn{6}{|l|}{ Smoking status $(\mathrm{n}=111 / 453)$} \\
\hline Previous/current smoker & 47 & $(42)$ & 155 & $(34)$ & 0.11 \\
\hline Place of contraction $(\mathrm{n}=125 / 456)$ & & & & & 0.001 \\
\hline Travel abroad & 40 & $(32)$ & 117 & $(26)$ & \\
\hline In Norway, known contact & 30 & (24) & 194 & (43) & \\
\hline In Norway, unknown contact & 55 & $(44)$ & 145 & $(32)$ & \\
\hline Time from COVID-19 onset, days, mean (SD) & 119 & $112(30)$ & 452 & $118(27)$ & \\
\hline Time from COVID-19 onset, days $(\mathrm{n}=119 / 452)$ & & & & & 0.006 \\
\hline $41-115$ & 72 & $(60)$ & 209 & $(46)$ & \\
\hline $116-200$ & 47 & $(40)$ & 243 & $(54)$ & \\
\hline \multicolumn{6}{|l|}{ Comorbidity } \\
\hline Asthma & 25 & $(20)$ & 52 & $(11)$ & 0.016 \\
\hline Chronic obstructive pulmonary disease & 4 & (3) & 5 & (1) & 0.10 \\
\hline Other chronic lung & & $(0)$ & 8 & (2) & 0.21 \\
\hline Lymphoma & & $(0)$ & & $(0)$ & - \\
\hline Other cancer & 4 & (3) & 6 & (1) & 0.23 \\
\hline Gastrointestinal & 5 & $(4)$ & 32 & $(7)$ & 0.30 \\
\hline Heart problems & 13 & $(10)$ & 27 & (6) & 0.11 \\
\hline Hypertension & 35 & $(28)$ & 86 & (19) & 0.034 \\
\hline Circulatory & 1 & (1) & 8 & (2) & 0.69 \\
\hline Chronic kidney disease & 2 & (2) & 5 & (1) & 0.65 \\
\hline Liver disease & 0 & $(0)$ & 1 & $(0)$ & 1 \\
\hline Neuromuscular & 6 & (5) & 3 & (1) & 0.004 \\
\hline Stroke & 4 & (3) & 8 & (2) & 0.30 \\
\hline Rheumatic & 1 & (1) & 23 & (5) & 0.039 \\
\hline Venous thromboembolism & 5 & $(4)$ & 11 & (2) & 0.35 \\
\hline Diabetes & 15 & $(12)$ & 16 & (3) & 0.001 \\
\hline Number of 16 comorbidities & & & & & 0.001 \\
\hline 0 & 52 & $(42)$ & 269 & (59) & \\
\hline 1 & 42 & (34) & 124 & (27) & \\
\hline$\geq 2$ & 31 & $(25)$ & 65 & (14) & \\
\hline Depression $(n=458) *$ & & $\mathrm{~N} / \mathrm{A}$ & 30 & (7) & - \\
\hline \multicolumn{6}{|l|}{ Symptoms during acute COVID-19 } \\
\hline Dyspnea $(n=125 / 449)$ & 88 & $(70)$ & 260 & (58) & 0.013 \\
\hline Confusion $(n=456) *$ & & $\mathrm{~N} / \mathrm{A}$ & 64 & $(14)$ & - \\
\hline Fever $(n=125 / 453)$ & 105 & $(84)$ & 331 & (73) & 0.013 \\
\hline
\end{tabular}




\subsection{Prevalence and Determinants of Symptom-Defined PTSD}

PTSD, as indicated by the DSM-5 criteria, was present in 11 (9.5\%) of hospitalized and $32(7.0 \%)$ of non-hospitalized individuals $(p=0.80)$ (Table 2$)$. Among women, $26 / 303(8.6 \%)$ had PTSD compared with $17 / 268(6.3 \%)$ among men $(p=0.31)$. The total PCL-5 score was higher in hospitalized than in non-hospitalized subjects, (mean 12.4 (SD 14.5) vs. 9.7 (11.3), $p=0.042$ ). In multivariable logistic regression analysis, there was no association between being hospitalized and the presence of symptom-defined PTSD. Being born outside of Norway was associated with PTSD, but none of the other covariates were significantly associated with PTSD (Figure 2).

Table 2. Symptoms of post-traumatic stress (PCL-5) $(n=572)$.

\begin{tabular}{cccccc}
\hline & Hospitalized & Non-Hospitalized & $p$ \\
\hline & $n$ & \multicolumn{3}{c}{} \\
\hline PTSD (DSM-5 scoring), number (\%) & 116 & $11(9.5)$ & 455 & $32(7.0)$ & 0.80 \\
PCL-5 total score (0-80 range), mean (SD) & 116 & $12.4(14.5)$ & 456 & $9.7(11.3)$ & 0.042 \\
\hline
\end{tabular}

PCL-5, PTSD symptom checklist for DSM-5; PTSD, post-traumatic stress disorder.

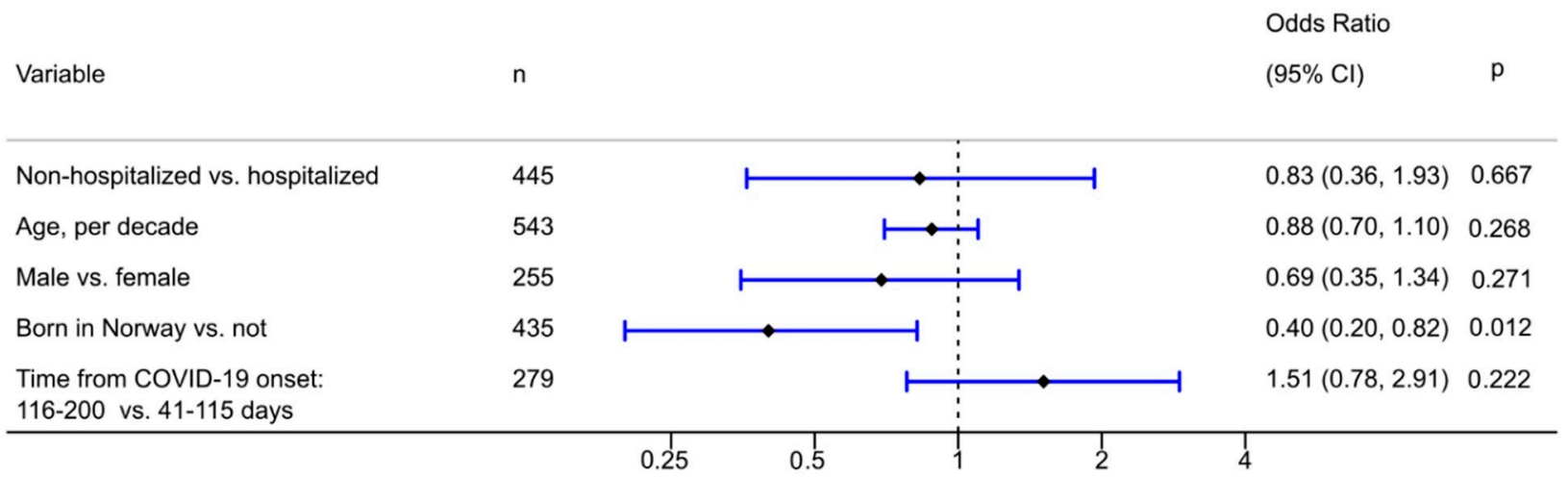

Figure 2. Odds ratios for the symptom-defined PTSD according to DSM-5 scoring with 95\% confidence intervals and $p$-values, multivariable logistic regression analysis $(n=559)$.

\subsection{Determinants of the PTSD Symptom Scores}

In the full sample data set, female sex, born outside Norway, and having dyspnea during COVID-19 were associated with higher PCL-5 total scores, while being hospitalized for COVID-19 was not (Table 3).

In stratified analyses, none of the independent variables was significantly associated with the PCL-5 total score in the hospitalized subjects. The pattern of associations with the PCL-5 total score was similar in the non-hospitalized sample as in the total sample with a few exceptions: living alone and having dyspnea during COVID-19 were associated with higher PTSD symptom scores (Table 3). In the analysis with the extended set of covariates among non-hospitalized subjects, male sex, being born in Norway, high symptom load during COVID-19 and confusions or reduced consciousness during acute COVID-19 were associated with higher PCL-5 total scores (Table 3). It is notable that time since COVID-19 onset was not associated with higher PCL-5 total scores in any of these four regression analyses. 


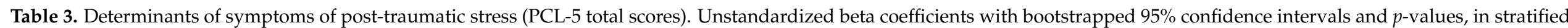
analyses. Multivariable linear regression.

\begin{tabular}{|c|c|c|c|c|c|c|c|c|}
\hline \multirow[b]{2}{*}{ Model } & \multicolumn{2}{|c|}{ All } & \multicolumn{2}{|c|}{ Hospitalized } & \multicolumn{4}{|c|}{ Non-Hospitalized } \\
\hline & \multicolumn{2}{|c|}{ (1) } & \multicolumn{2}{|c|}{ (2) } & \multicolumn{2}{|c|}{ (3) } & \multicolumn{2}{|c|}{ (4) } \\
\hline & Coef. & $95 \% \mathrm{CI}$ & Coef. & $95 \% \mathrm{CI}$ & Coef. & $95 \% \mathrm{CI}$ & Coef. & $95 \% \mathrm{CI}$ \\
\hline \multicolumn{9}{|l|}{ Cohort } \\
\hline Hospitalized & 0 & & & & & & & \\
\hline Non-hospitalized & -1.05 & {$[-4.38,2.28]$} & & & & & & \\
\hline \multicolumn{8}{|l|}{ Sex } & {$[-0.70,0.73]$} \\
\hline $\begin{array}{c}\text { sex } \\
\text { Female }\end{array}$ & 0 & & 0 & & 0 & & 0 & \\
\hline \multicolumn{9}{|l|}{ Born in Norway } \\
\hline No & 0 & & 0 & & 0 & & 0 & \\
\hline Yes & $-6.82^{* * *}$ & {$[-9.82,-3.82]$} & -5.64 & {$[-12.97,1.68]$} & $-7.17^{* * *}$ & {$[-10.45,-3.89]$} & $-5.14^{* *}$ & {$[-8.59,-1.68]$} \\
\hline \multicolumn{9}{|l|}{ Highest attained education } \\
\hline Primary school (<11 years) & 0 & & 0 & & 0 & & 0 & \\
\hline Secondary school (11-13 years) & 2.14 & {$[-1.37,5.65]$} & 2.57 & {$[-4.90,10.03]$} & 0.92 & {$[-3.33,5.16]$} & 1.69 & {$[-1.97,5.35]$} \\
\hline University ( $>13$ years) & 1.34 & {$[-2.28,4.95]$} & 5.75 & {$[-2.41,13.91]$} & -0.58 & {$[-4.74,3.58]$} & 0.30 & {$[-3.15,3.75]$} \\
\hline \multicolumn{9}{|l|}{ Marital status } \\
\hline Single/divorced/widowed & 0 & & 0 & & 0 & & 0 & \\
\hline \multicolumn{9}{|l|}{ No. of 16 comorbidities } \\
\hline 0 & 0 & & 0 & & 0 & & 0 & \\
\hline 1 & 0.16 & {$[-2.12,2.43]$} & 1.17 & {$[-6.54,8.89]$} & -0.10 & {$[-2.41,2.20]$} & -0.99 & {$[-3.05,1.07]$} \\
\hline$\geq 2$ & 2.60 & {$[-0.42,5.62]$} & 3.76 & {$[-3.60,11.12]$} & 2.62 & {$[-0.78,6.02]$} & 1.87 & {$[-1.66,5.41]$} \\
\hline \multicolumn{9}{|l|}{ Dyspnea during COVID-19 } \\
\hline No & 0 & & 0 & & 0 & & & \\
\hline Yes & $3.68^{* * *}$ & {$[1.80,5.57]$} & 2.73 & {$[-2.51,7.97]$} & $3.66^{* * *}$ & {$[1.58,5.73]$} & & \\
\hline \multicolumn{9}{|l|}{ Fever during COVID-19 } \\
\hline No & 0 & & 0 & & 0 & & & \\
\hline Yes & 1.80 & {$[-0.26,3.86]$} & 0.98 & {$[-7.46,9.41]$} & 1.70 & {$[-0.39,3.78]$} & & \\
\hline
\end{tabular}


Table 3. Cont.

\begin{tabular}{|c|c|c|c|c|c|c|c|c|}
\hline \multirow[b]{2}{*}{ Model } & \multirow{2}{*}{\multicolumn{2}{|c|}{$\begin{array}{l}\text { All } \\
(1)\end{array}$}} & \multirow{2}{*}{\multicolumn{2}{|c|}{$\begin{array}{c}\text { Hospitalized } \\
\text { (2) }\end{array}$}} & \multicolumn{4}{|c|}{ Non-Hospitalized } \\
\hline & & & & & & & & \\
\hline \multicolumn{9}{|c|}{ Time since COVID-19 onset, days } \\
\hline $41-115$ & 0 & & 0 & & 0 & & 0 & \\
\hline $116-200$ & 0.63 & {$[-1.40,2.66]$} & 2.33 & {$[-3.51,8.17]$} & 0.59 & {$[-1.49,2.68]$} & 0.16 & {$[-1.78,2.11]$} \\
\hline \multicolumn{9}{|c|}{ History of depression ${ }^{1}$} \\
\hline No & & & & & & & 0 & \\
\hline Yes & & & & & & & $4.58 *$ & {$[0.19,8.97]$} \\
\hline \multicolumn{9}{|c|}{ No. of 23 symptoms during COVID-19 1} \\
\hline $0-5$ & & & & & & & 0 & \\
\hline $6-9$ & & & & & & & 0.59 & {$[-1.74,2.93]$} \\
\hline $10-23$ & & & & & & & $5.59^{* * *}$ & {$[2.94,8.24]$} \\
\hline \multicolumn{9}{|c|}{ Confusion during COVID-19 1} \\
\hline No & & & & & & & 0 & \\
\hline Yes & & & & & & & $6.80^{* * *}$ & {$[3.12,10.49]$} \\
\hline$n$ & 531 & & 98 & & 433 & & 444 & \\
\hline R-squared & 0.11 & & 0.13 & & 0.13 & & 0.24 & \\
\hline
\end{tabular}




\section{Discussion}

We investigated post-traumatic stress symptoms in a geographically defined population of hospitalized and non-hospitalized COVID-19-infected subjects on average 3 months after symptom onset. The prevalence of symptom-defined PTSD was $9.5 \%$ in hospitalized and $7.0 \%$ in non-hospitalized patients. Hospitalization was not associated with PTSD, while symptom load during COVID-19 added value to well known risk factors for determining the PTSD symptom score.

This is the first study that invited all positive SARS-CoV-2 subjects within a large geographical area during the first wave of the pandemic. Thus, our sample reflects a wide range of symptoms and trajectories of COVID-19 survivors.

Our prevalence rates are in the lower range of the $7-34 \%$, which was reported in other cohorts of COVID-19 survivors following hospitalization at comparable time points [6-8,18-21], and much lower than the 96\% reported during hospitalization in a study using the PCL-C, a civilian version of a PTSD questionnaire based on DSMIV [22]. Two of the studies also comprised both hospitalized and non-hospitalized subjects $[7,21]$. Horn et al. assessed 180 subjects at about 7 weeks after COVID-19 onset also using the PCL-5 and reported comparable prevalence rates of PTSD as those in our study. De Lorenzo et al. assessed 185 subjects recruited in the emergency department and reported a prevalence of PTSD of $22 \%$ using the impact of event scale. One possible explanation for the varying prevalence is that studies use different definitions for caseness of PTSD, such as different cut-offs on a continuous symptom scale or DSM-5-based scores, as in the present study. Several other factors may also explain the large differences in prevalence estimates of reported PTSD between cohorts of COVID-19-infected individuals. These include the accessibility of adequate medical treatment in the healthcare system, people's trust in health and welfare systems, and their access to factual or intimidating information. Compared with many other countries, Norway had sufficient capacity in a free healthcare system, low or no excess mortality from the pandemic, state financial support for the needy, and generally high confidence in the health and welfare schemes during the initial stage of the COVID-19 pandemic. Norwegians reported the highest perceived efficacy of governmental reactions to COVID-19 in a recent study in six countries [23]. Probably for the same reasons, Norway also had lower prevalence of pandemic-related stress reactions in the general population than many other countries [14].

In this study, the prevalence rates of PTSD, as well as the severity of PTSD symptoms after adjustment for comorbidity, did not differ between hospitalized and non-hospitalized patients, which deviates from previous studies reporting higher odds of PTSD in hospitalized than non-hospitalized patients [7,21]. On the one hand, hospitalization is likely to increase the perception of how critical the event is for people's lives, which is usually associated with more post-traumatic stress $[24,25]$. The experience of how dangerous the infection can be may also lead to higher stress reactions [26,27]. On the other hand, hospitalization may also have been perceived as caring and safe, which may have reduced the stress reactions. Care that emphasizes information, calming, sense of safety, self-efficacy and hope may reduce the risk for developing PTSD [28]. During the first pandemic wave in Norway, the threshold for hospitalization might have been high, as home isolation was generally accepted by the patients, and the community health providers had daily telephone contact to monitor those in need for hospitalization. However, some may develop PTSD symptoms after a longer time since the event than the follow-up period of this study $[29,30]$. Therefore, prevalence rates and predictors of PTSD should be assessed after longer follow-up in future studies.

Regardless of hospitalization or not, COVID-19 symptom load was associated with higher levels of post-traumatic stress reactions. This makes sense since a higher symptom burden can result in a greater experience of threat. We find it likely that this is especially true for dyspnea which may be an anxiety- and fear-inducing symptom. However, we did not specifically assess threat perception in our study. In this study, female subjects, those born outside of Norway and those with a history of depression displayed the highest odds 
of having PTSD symptoms after 3 months. This supports previous findings of a higher risk of PTSD following COVID-19 among females and those with a history of psychiatric disease [7]. Citizens born outside Norway may have less access to information and less trust in the health care service or the authorities' handling of the pandemic, and should be offered information and care that is adapted to their specific situation.

The prevalence of PTSD in the present study was at the level reported in populations after natural catastrophes and disasters, typically 5-10\% [29] and in some general populations during the current pandemic of 3-8\% [31-33]. However, the prevalence was smaller than that reported in a recent Norwegian study during the early stages of COVID-19 of $12.5 \%$ in men and $19.5 \%$ in women [14]. We believe this indicates that the generic fear of contracting COVID-19 and the social isolation and quarantine impacts PTSD symptoms as much as having the viral infection itself. Furthermore, some of the variation in prevalence rates could be attributed to the sampling method, where the studies with the highest prevalence recruited through public channels and social media, biased by persons with symptoms.

Our study has some limitations. The overall response rate in the non-hospitalized sample was about $50 \%$ and somewhat biased towards females and subjects $>50$ years of age. The response rate was low in three districts of Oslo with a high proportion of immigrants. This pattern of non-response is in line with our expectations and common in epidemiological surveys $[34,35]$. This may cause non-response bias of both the main variable and covariates, which is difficult to control for and may limit generalizability. It is possible that the elderly with much comorbidity and younger people with few problems, as well as many with limited Norwegian language skills, were less willing to respond, and this may overestimate the prevalence of PTSD. Furthermore, we did not include other relevant factors such as living with children, or death of a family member, that have been associated with PTSD risk in other COVID-19 studies [6], or general risk factors for PTSD such as details on previous psychiatric disease, although depression was included as a self-reported item in the non-hospitalized sample. Finally, COVID-19 symptoms were retrospectively reported and subject to recall bias, which may inflate actual symptoms.

In conclusion, persons infected during the first pandemic wave of COVID-19 in Norway had a lower prevalence of PTSD than those in previous reports. Being hospitalized for COVID-19 was not associated with higher prevalence of PTSD than was being infected with COVID-19 in general. Dyspnea and overall symptom load were associated with increased risk of persistent PTSD symptoms, in addition to being female, being born outside Norway and having a history of depression. These characteristics may serve to identify subjects that could benefit from follow-up with assessment for PTSD symptoms, regardless of having been hospitalized or not.

Author Contributions: Conceptualization, G.E., K.S.; methodology, G.E., K.S., T.H., W.G., T.D.; software, K.S.; validation, K.S., T.H.; formal analysis, K.S., G.E., T.H.; investigation, G.E., K.S., W.G.; resources, G.E., K.S., W.G.; data curation, K.S.; writing—original draft preparation, G.E., K.S.; writing—review and editing, G.E., K.S., T.H., W.G., T.D.; visualization, K.S.; project administration, G.E., K.S., W.G. All authors have read and agreed to the published version of the manuscript.

Funding: This work was supported by internal funds in the participating institutions, and no external funding was involved.

Institutional Review Board Statement: The Regional Committees for Medical and Health Research Ethics, Health Region South East (PROLUN approval no. 2020/125384, PROTROM approval no. 2020/149384) and the Data Protection Officer at Ahus approved both studies. PROLUN is registered in Clinicaltrial.gov (NCT04535154).

Informed Consent Statement: Informed consent was obtained from all subjects involved in the study.

Data Availability Statement: The data presented in this study are available on request from the corresponding author. The data are not publicly available due to local restrictions. 
Conflicts of Interest: Einvik reports grants from AstraZeneca AS, grants from Boehringer Ingelheim, outside the submitted work; Ghanima reports personal fees from Novartis, grants from Pfizer, personal fees from Amgen, grants and personal fees from Bayer, personal fees from Sanofi, outside the submitted work. The other authors declare no conflict of interest.

\section{References}

1. WHO. Coronavirus Disease (COVID-19) Dashboard. Available online: https://covid19.who.int/ (accessed on 17 December 2020).

2. Nystad, W.; Hjellvik, V.; Larsen, I.K.; Ariansen, I.; Helland, E.; Johansen, K.I.; Gulbrandsen, J.; Gulseth, H.L.; Eide, H.N.; Haberg, S.E.; et al. Underlying conditions in adults with COVID-19. Tidsskr. Nor. Legeforening 2020, 140. [CrossRef]

3. Asmundson, G.J.G.; Taylor, S. Coronaphobia: Fear and the 2019-nCoV outbreak. J. Anxiety Disord. 2020, 70, 102196. [CrossRef] [PubMed]

4. Parker, A.M.; Sricharoenchai, T.; Raparla, S.; Schneck, K.W.; Bienvenu, O.J.; Needham, D.M. Posttraumatic stress disorder in critical illness survivors: A metaanalysis. Crit. Care Med. 2015, 43, 1121-1129. [CrossRef]

5. $\quad$ Badenoch, J.; Cross, B.; Hafeez, D.; Song, J.; Watson, C.; Butler, M.; Nicholson, T.R.; Rooney, A.G. Post-traumatic symptoms after COVID-19 may (or may not) reflect disease severity. Psychol. Med. 2020. [CrossRef]

6. Liu, D.; Baumeister, R.F.; Veilleux, J.C.; Chen, C.; Liu, W.; Yue, Y.; Zhang, S. Risk factors associated with mental illness in hospital discharged patients infected with COVID-19 in Wuhan, China. Psychiatry Res. 2020, 292, 113297. [CrossRef]

7. De Lorenzo, R.; Conte, C.; Lanzani, C.; Benedetti, F.; Roveri, L.; Mazza, M.G.; Brioni, E.; Giacalone, G.; Canti, V.; Sofia, V.; et al. Residual clinical damage after COVID-19: A retrospective and prospective observational cohort study. PLoS ONE 2020, 15, e0239570. [CrossRef]

8. Chang, M.C.; Park, D. Incidence of Post-Traumatic Stress Disorder After Coronavirus Disease. Healthcare 2020, 8, 373. [CrossRef]

9. Lerum, T.V.; Aalokken, T.M.; Bronstad, E.; Aarli, B.; Ikdahl, E.; Lund, K.M.A.; Durheim, M.T.; Rodriguez, J.R.; Meltzer, C.; Tonby, K.; et al. Dyspnoea, lung function and CT findings three months after hospital admission for COVID-19. Eur. Respir. J. 2020. [CrossRef]

10. Stavem, K.; Ghanima, W.; Olsen, M.K.; Gilboe, H.M.; Einvik, G. Persistent symptoms 1.5-6 months after COVID-19 in nonhospitalised subjects: A population-based cohort study. Thorax 2020. [CrossRef]

11. Blevins, C.A.; Weathers, F.W.; Davis, M.T.; Witte, T.K.; Domino, J.L. The Posttraumatic Stress Disorder Checklist for DSM-5 (PCL-5): Development and Initial Psychometric Evaluation. J. Trauma. Stress 2015, 28, 489-498. [CrossRef]

12. Weathers, F.W.; Litz, B.T.; Keane, T.M.; Palmieri, P.A.; Marx, B.P.; Schnurr, P.P. The PTSD Checklist for DSM-5 (PCL-5)—Standard. Available online: www.ptsd.va.gov/professional/assessment/adult-sr/ptsd-checklist.asp (accessed on 18 December 2020).

13. Using the PTSD Checklist for DSM-5. Available online: https://www.ptsd.va.gov/professional/assessment/documents/usingPCL5.pdf (accessed on 20 February 2021).

14. Bonsaksen, T.; Heir, T.; Schou-Bredal, I.; Ekeberg, O.; Skogstad, L.; Grimholt, T.K. Post-Traumatic Stress Disorder and Associated Factors during the Early Stage of the COVID-19 Pandemic in Norway. Int. J. Environ. Res. Public Health 2020, 17, 9210. [CrossRef] [PubMed]

15. Katz, J.N.; Chang, L.C.; Sangha, O.; Fossel, A.H.; Bates, D.W. Can comorbidity be measured by questionnaire rather than medical record review? Med. Care 1996, 34, 73-84. [CrossRef]

16. Charlson, M.E.; Pompei, P.; Ales, K.L.; MacKenzie, C.R. A new method of classifying prognostic comorbidity in longitudinal studies: Development and validation. J. Chronic. Dis. 1987, 40, 373-383. [CrossRef]

17. WHO/ISARIC. COVID-19 Case Record Form. Global COVID-19 Clinical Platform Novel Coronavirus (COVID-19)-Rapid Version. Available online: https://media.tghn.org/medialibrary/2020/09/ISARIC_COVID-19_RAPID_CRF_25Aug20.pdf (accessed on 20 February 2021).

18. Poyraz, B.C.; Poyraz, C.A.; Olgun, Y.; Gurel, O.; Alkan, S.; Ozdemir, Y.E.; Balkan, I.I.; Karaali, R. Psychiatric morbidity and protracted symptoms after COVID-19. Psychiatry Res. 2021, 295, 113604. [CrossRef]

19. Cai, X.; Hu, X.; Ekumi, I.O.; Wang, J.; An, Y.; Li, Z.; Yuan, B. Psychological Distress and Its Correlates Among COVID-19 Survivors During Early Convalescence Across Age Groups. Am. J. Geriatr. Psychiatry 2020, 28, 1030-1039. [CrossRef] [PubMed]

20. Gu, Y.; Zhu, Y.; Xu, F.; Xi, J.; Xu, G. Factors associated with mental health outcomes among patients with COVID-19 treated in the Fangcang shelter hospital in China. Asia Pac. Psychiatry 2020, e12443. [CrossRef]

21. Horn, M.; Wathelet, M.; Fovet, T.; Amad, A.; Vuotto, F.; Faure, K.; Astier, T.; Noel, H.; Duhem, S.; Vaiva, G.; et al. Is COVID-19 Associated With Posttraumatic Stress Disorder? J. Clin. Psychiatry 2020, 82. [CrossRef]

22. Bo, H.X.; Li, W.; Yang, Y.; Wang, Y.; Zhang, Q.; Cheung, T.; Wu, X.; Xiang, Y.T. Posttraumatic stress symptoms and attitude toward crisis mental health services among clinically stable patients with COVID-19 in China. Psychol. Med. 2020. [CrossRef]

23. Maekelae, M.J.; Reggev, N.; Dutra, N.; Tamayo, R.M.; Silva-Sobrinho, R.A.; Klevjer, K.; Pfuhl, G. Perceived efficacy of COVID-19 restrictions, reactions and their impact on mental health during the early phase of the outbreak in six countries. R. Soc. Open Sci. 2020, 7, 200644. [CrossRef] [PubMed]

24. Berntsen, D.; Rubin, D.C. The centrality of event scale: A measure of integrating a trauma into one's identity and its relation to post-traumatic stress disorder symptoms. Behav. Res. Ther. 2006, 44, 219-231. [CrossRef]

25. Blix, I.; Birkeland, M.S.; Solberg, Ø.; Hansen, M.B.; Heir, T. The Launching and Ensnaring Effects of Construing a Traumatic Event as Central to One's Identity and Life Story. Appl. Cogn. Psychol. 2016, 30, 526-531. [CrossRef] 
26. Heir, T.; Piatigorsky, A.; Weisaeth, L. Longitudinal changes in recalled perceived life threat after a natural disaster. Br. J. Psychiatry 2009, 194, 510-514. [CrossRef] [PubMed]

27. Heir, T.; Blix, I.; Knatten, C.K. Thinking that one's life was in danger: Perceived life threat in individuals directly or indirectly exposed to terror. Br. J. Psychiatry 2016, 209, 306-310. [CrossRef] [PubMed]

28. Heir, T.; Hussain, A.; Weisæth, L. Managing the after-effects of disaster trauma-The essentials of early intervention. Eur. Psychiatr. Rev. 2008, 1, 66-69.

29. Bryant, R.A. Post-traumatic stress disorder: A state-of-the-art review of evidence and challenges. World Psychiatry 2019, 18, 259-269. [CrossRef]

30. Lee, A.M.; Wong, J.G.; McAlonan, G.M.; Cheung, V.; Cheung, C.; Sham, P.C.; Chu, C.M.; Wong, P.C.; Tsang, K.W.; Chua, S.E. Stress and psychological distress among SARS survivors 1 year after the outbreak. Can. J. Psychiatry 2007, 52, 233-240. [CrossRef]

31. Tang, W.; Hu, T.; Hu, B.; Jin, C.; Wang, G.; Xie, C.; Chen, S.; Xu, J. Prevalence and correlates of PTSD and depressive symptoms one month after the outbreak of the COVID-19 epidemic in a sample of home-quarantined Chinese university students. J. Affect. Disord. 2020, 274, 1-7. [CrossRef]

32. Liu, N.; Zhang, F.; Wei, C.; Jia, Y.; Shang, Z.; Sun, L.; Wu, L.; Sun, Z.; Zhou, Y.; Wang, Y.; et al. Prevalence and predictors of PTSS during COVID-19 outbreak in China hardest-hit areas: Gender differences matter. Psychiatry Res. 2020, 287, 112921. [CrossRef]

33. Casagrande, M.; Favieri, F.; Tambelli, R.; Forte, G. The enemy who sealed the world: Effects quarantine due to the COVID-19 on sleep quality, anxiety, and psychological distress in the Italian population. Sleep Med. 2020, 75, 12-20. [CrossRef]

34. Krogstad, H.; Loge, J.H.; Grotmol, K.S.; Kaasa, S.; Kiserud, C.E.; Salvesen, O.; Hjermstad, M.J. Symptoms in the general Norwegian adult population-Prevalence and associated factors. BMC Public Health 2020, 20, 988. [CrossRef] [PubMed]

35. Galea, S.; Tracy, M. Participation rates in epidemiologic studies. Ann. Epidemiol. 2007, 17, 643-653. [CrossRef] 